TRABAJOS DE PREHISTORIA

52. n. ${ }^{\circ}$ 1. 1995, pp. 109-126

\section{FENICIOS Y AUTÓCTONOS EN TARTESSOS. CONSIDERACIONES SOBRE LAS RELACIONES COLONIALES Y LA DINÁMICA DE CAMBIO EN EL SUROESTE DE LA PENÍNSULA IBÉRICA}

\author{
PHOENICIANS AND NATIVE PEOPLE IN \\ TARTESSOS. REFLECTIONS \\ CONCERNING THE COLONIAL \\ RELATIONSHIP AND CHANGE IN THE \\ S.W. OF THE IBERIAN PENINSULA
}

\section{CARLOS G. WAGNER (*)}

\section{RESUMEN}

La colonización fenicia durante los siglos VIII y VI a.C. se concibe como una forma de comercio a larga distancia y de intercambio desigual con ulteriores implicaciones en el cambio social -pero no cultural- de las comunidades campesinas de la Edad del Bronce Final del Suroeste de la Península Ibérica, debido a la dependencia de las élites locales de aquellas relaciones y a la desestructuración económica que provocan. Se discute la importancia del trabajo del metal. La presencia fenicia en el interior, en contraste con los asentamientos costeros, se comenta para comprender mejor la fuerte aculturación orientalizante que se observa en el registro arqueológico (evidencia funeraria).

\section{ABSTRACT}

Phoenician colonization during the VIIIth and VIIth centuries B.C. is perceived economically as based on long/ distance trade and unequal exchange. This has further

(*) Departamento de Historia Antigua. Facultad de Geografía e Historia. Universidad Complutense. 28040 Madrid.

El artículo fue remitido en su versión final el 8-V-95. implications on social -though not cultural-change in the Late Bronze Age village communities in the S.W. of the Iberian Peninsula, given the local elite's dependence on those relations and the economic destructuration which they brought about. The importance of metalworking is discussed. We comment on the Phoenician presence inland, in contrast to the coastal settlements, as a way of understanding better the strong orientalizing acculturation observed in archaeological data (burial evidence).

Palabras clave: Metalurgia. Intercambio desigual. Cambio cultural. Orientalizante

Key words: Metallurgy. Unequal exchange. Cultural change. Orientalizing.

\section{INTRODUCCIÓN}

Pese al avance de recientes aproximaciones (Plácido, 1989, 1993a y 1993b; Cruz Andreotti, 1991) logrando una mejor contextualización de la imagen de Tartessos como producto de un proceso histórico -el de la Grecia arcaica- que nos proporcionan las escasas noticias de las fuentes literarias, lo insuficiente de su informa- 
ción. con su alto contenido de ambigüedad (Wagner, 1986a: De Hoz. 1989) hacen recaer el peso de la investigación en el estudio de los materiales arqueológicos. Este estudio, claro está, se efectúa según un enfoque y una metodología que responden, en realidad, a las ideas que tiene cada investigador de los fenómenos históricos, de lo que entiende por los factores que propician cambios y transformaciones en la dinámica de los acontecimientos y los procesos que los configuran. Algo, al parecer, tan evidente que casi nunca se explicita.

Así, toda la discusión sobre las diversas interpretaciones que reposan en el análisis del registro arqueológico versa, en último término, sobre la forma de trabajar de cada uno, condicionada, se reconozca o no, por tales ideas previas. Hay quien, con una concepción idealista de la cultura y de los aconteceres históricos, se sirve sin más de los datos arqueológicos y literarios, ordenándolos e interpretándolos en una síntesis descriptiva basada en procedimientos inductivos según el más puro proceder normativista. Esta fuerte confianza en los datos en sí mismos, y en la información que proporcionan, se adereza otras veces con explicaciones $a$ posteriori, utilizadas para justificar, implícita o explícitamente, la ordenación y selección mismas de los datos previamente realizadas. En tales ocasiones predominan las de carácter historicista y difusionista, y hay también algunas muestras de un acusado eclecticismo (Iudice Gamito, 1988) de decepcionantes resultados. Sólo en contadas ocasiones (Barceló, 1992) se procede a un planteamiento previo del modelo teórico del que se nutren las hipótesis a validar y contrastar.

No obstante el dato en sí no es algo valioso, sino que adquiere su significado dentro de un marco teórico en el que se contextualiza, por lo que estoy totalmente de acuerdo con Carrilero (1993: 164) cuando afirma que: "el dato no es algo aséptico que aparece en una excavación arqueológica o en un texto escrito suceptible de ser interpretado, el dato es una elaboración intelectual de ordenación y evaluación según un modelo explícito, por lo tanto, éste constituye una síntesis, un punto de llegada que nos sirve para construir hipótesis que han de ser validadas o contrastadas". Así, el modelo que a lo largo de estas páginas se propone para su discusión, y que de forma menos articulada he defendido en publicaciones anteriores (Wagner, 1991 y 1993a). está elaborado desde una perspectiva que concibe la expansión fenicia arcaica (siglos VIII-VI a.C.) como una modalidad de comercio lejano inserta en un sistema mundial de relaciones centro/periferia, y caracterizada por una estrategia dinamizadora de los intercambios que origina la colonización, con la aparición de asentamientos próximos a las zonas en que se efectúan aquellos, y en la que la necesaria explicación de los procesos que ligan el centro y la periferia (Gilman, 1993: 107) se articula en un conjunto de relaciones sociales, económicas y políticas que se establecen en un contexto de intercambio desigual (Wagner, 1991: 15 y 24, 1993a: 105 y e.p.). Un modelo que, desde la perspectiva de la arqueoantropología materialista, pone el énfasis en las relaciones sociales, la desigualdad y la explotación, en vez de en los aspectos puramente culturales que creo justificadamente criticados (Alvar, 1994: 39), y cuyas implicaciones son:

a) el carácter aldeano de la formación social tartésica antes de su contacto con los colonizadores fenicios; una sociedad estructurada en torno al parentesco y con un modo de producción doméstico como forma económica dominante, que se verá transformada a consecuencia del contacto colonial. Contacto que se articula en el ámbito de un

b) comercio colonial, como una modalidad de comercio lejano y de intercambio desigual que aquél conlleva como modos de transferir riqueza desde una formación social a otra, dando como resultado

c) una transformación que se produce, no en el sentido de "progreso" histórico a que tantas veces se alude y sin las consecuencias "modernizantes" ("apogeo económico", "economía de mercado") que se le atribuyen, y en la que es preciso distinguir el cambio cultural del cambio social que tan frecuentemente se confunden. Una transformación que, por el contrario, permite a las élites emergentes utilizar el comercio colonial para apropiarse del excedente, manteniendo una posición de prestigio y privilegio en la que el control de la redistribución favorece los intereses de los fenicios al capacitarlas para movilizar la fuerza de trabajo que éstos demandan en forma de materias primas, pero que acentúa la tensión con las formas de organización tradicionales, favoreciendo el tránsito a formas acusadas de desigualdad económica, al 
tiempo que produce dependencia técnica y subordinación económica. En tal contexto

d) la aculturación orientalizante se constituye en una estrategia no violenta de explotación colonial, mediante la cual las élites autóctonas quedan subordinadas a las decisiones e intereses que se imponen desde la jerarquía colonial, y

e) la presencia colonial en el interior en un medio de dinamizar los intercambios y de atenuar las tensiones en el centro (las ciudades de Fenicia) mediante la manipulación de la periferia.

Procede, por tanto, la validación y contrastación de tales propuestas. A tal respecto el registro arqueológico no es lo completo que se desearía, consecuencia en gran parte de que las investigaciones arqueológicas se hallan realizado muchas veces desde posiciones puramente intuitivas y especulativas sin más referencias teóricas de partida (Carrilero, 1993: 163; López Castro, 1993), pese a todo lo cual la documentación disponible no desarmoniza, en mi opinión, con la interpretación que propongo.

\section{EL CARÁCTER DE LA FORMACIÓN SOCIAL TARTÉSICA}

Pese a los variados intentos por despejarla, el carácter de la formación social tartésica antes de su contacto con los fenicios continúa siendo en gran medida una incógnita. Ello no ha impedido que se realicen diversas aproximaciones desde otras tantas perspectivas. Algunas, como la que defiende la existencia de las élites con el argumento de que es precisamente a estas élites a quién va destinado el comercio fenicio y sin cuya presencia no habría podido articularse la relación implícita en el comercio colonial, constituyen un claro ejemplo de hipótesis ad hoc, que de momento no está contrastada en el registro arqueológico.

Como bien ha observado Gilman (1993: 109), la evidencia sobre la organización económica y social que fundamente cualquier hipótesis sobre el carácter de la formación social tartésica ha de ser aún desarrollada, al mismo tiempo que "el impacto de los contactos fenicios y griegos durante el Primer Milenio en Iberia sólo puede proponerse en un ámbito que dé primacía explicativa al marco político y económico del intercambio".
Como también se ha señalado recientemente (Carrilero, 1993: 166) "de momento no constatamos una sociedad que esté claramente estratificada en el Bronce Final, ni que existan unas élites definidas, sencillamente porque no se han puesto los medios ni teóricos ni prácticos para desentrañar que organización social encuentran los fenicios en el sur peninsular a su llegada a nuestras costas". Los únicos vestigios que podían inducirnos a pensar en la existencia de élites en las comunidades del Bronce Final, las estelas decoradas del Suroeste, presentan un grado de variabilidad tan alto en los patrones iconográficos que se puede deducir de ello la inexistencia de una definición nítida del prestigio, lo que indicaría una ausencia de cohesión social entre las élites representadas en ellas (Barceló, 1992: 269) o, sencillamente, la inexistencia de tales élites al corresponder las estelas a un sistema de representación de rangos en una "sociedad donde los guerreros participen en la producción y donde exista una total ausencia de lazo directo entre poder y riqueza" (Carrilero, 1993: 166). Una interpretación distinta de las estelas, que las desvincula parcialmente del supuesto contexto funerario a que normalmente se adscriben (Bendala Galán et alii, 1994: 66 ss.), las considera señales en el territorio, a modo de indicadores de rutas ganaderas y comerciales (Ruiz-Gálvez Priego y Galán Domingo, 1991) que trasmiten al mismo tiempo, mediante un lenguaje iconográfico y simbólico complejo, ideas de posesión territorial a la vez que expresan relaciones sociales, aunque se reconoce también su vinculación con grupos elitistas que se están consolidando en una zona marginal del principal foco tartésico (Galán Domingo, 1993). Como se ve, ante la falta de otros datos, las estelas pueden interpretarse en sentidos muy diferentes, sobre todo si se piensa que la metalurgia y el comercio no siempre son indicios seguros de complejidad sociocultural.

Aunque en ocasiones se me ha atribuido, no he afirmado nunca que las comunidades tartésicas del Bronce Final, o preorientalizantes, constituyeran sociedades igualitarias. Por el contrario, he insistido desde un principio en su carácter incipientemente jerarquizado (Wagner, 1983: 12; 1986b: 154; 1992: 93 y 1993a: 104), lo que no implica la existencia necesaria de élites desarrolladas y estratificación social sino posiciones de prestigio al frente de una red redistributiva suprafamiliar. Posiciones centralizadas 
de liderazgo que en términos políticos denominamos jefaturas y que no suponen la formación de un grupo social de índole aristocrática capaz de realizar la apropiación de la tierra comunitaria. Por eso estoy en desacuerdo con aquéllos que consideran el mundo tartésico del Bronce Final como una cultura compleja y muy elaborada. A este respecto me parece que gran parte de la discrepancia proviene de los indicadores que cada uno considera adecuados a un determinado nivel de complejidad cultural, y que algunos arqueólogos y prehistoriadores identifican, de manera errónea, sociedad aldeana con "ambiente neolítico". Yo interpreto que el registro arqueológico del Bronce Final, allí donde es mínimamente fiable, nos muestra unas comunidades aldeanas que se caracterizan por la presencia generalizada de poblados de cabañas, cerámicas a mano, escasa o muy localizada actividad metalúrgica, utillaje mayoritariamente lítico y un modo de producción doméstico (Wagner, 1983: 9, 1991: 16, 1992: 90 ss.; Carrilero, 1993: 169), lo que en mi opinión no constituyen muestras de una complejidad cultural acusada ni de una compleja estructura socieconómica. La ausencia de necrópolis conocidas de este periodo añade una dificultad más a la contrastación de mi hipótesis, y de cualquier otra, pero lo que conocemos de los enterramientos más antiguos de la necrópolis de Las Cumbres, como el túmulo 1 , sugiere la existencia de prácticas funerarias de carácter comunitario (Ruiz Mata, 1991b: 215 ss.; Ruiz Mata y Pérez, 1989: 292 ss.) que encajan bien con lo propuesto.

Dado que, sin embargo, la metalurgia ha sido uno de los elementos principales sobre el que se ha generado la idea de una notoria complejidad cultural tartésica durante el Bronce Final, la tomaré ahora como objeto central de mi análisis. Identificar automáticamente la presencia de trabajo metalúrgico con altos niveles de complejidad sociocultural constituye un error hace tiempo señalado (Rowlands, 1971). Por ello no interesa tanto conocer la supuesta antigüedad de las técnicas minerometalúrgicas entre las poblaciones del Suroeste peninsular, sino evaluar su incidencia concreta en el ámbito de los procesos de trabajo locales y de las relaciones socioeconómicas dominantes. El que se conociese el beneficio de la plata desde el segundo milenio (Aubet, 1991: 36) parece un dato en sí mismo no demasiado significativo, si no lo contextualizamos debidamente en un determinado modo de producción en que adquiera significado. En otras palabras, este dato en sí no constituye indicador fiable que nos sitúe en un determinado nivel de complejidad cultural. Tal y como ha mostrado Carrilero (1992a: 970) en su análisis de las sociedades de la Prehistoria reciente en el Sureste peninsular, la experiencia histórica y etnoantropológica coin-ciden en señalar que la presencia de artesanos especialistas no equivale automáticamente a la existencia de una acusada división del trabajo, sino que éstos son perfectamente posibles en un marco caracterizado por las relaciones entre linajes cuyas actividades productivas dependan de la agricultura y la ganadería (Rowlands, 1971: 215; Godelier, 1974: 275 ss.). Del mismo modo, ciertas tareas de interés común pueden ser emprendidas a niveles más altos que las simples unidades domésticas productivas por grupos de descendencia o por la comunidad de aldea en su conjunto (Sahlins, 1972: 121). Y la propia experiencia empírica viene a mostrar cómo la metalurgia fue conocida durante un milenio en Europa antes que la intensificación de los sistemas de subsistencia creara el contexto social adecuado para la acumulación de riqueza y estimulara el desarrollo de la tecnología (Gilman, 1981: 19). Por consiguiente habría que averiguar si tal intensificación tuvo lugar. A este respecto se discute acerca de la expansión agrícola que habría, según algunos, carac-terizado el periodo (Aubet, 1977-8: 106; Barceló, 1992: 266; Carrilero, 1993: 165) lo que tal vez se perciba también en una mayor estabilidad del hábitat (Galán Domingo, 1993: 57 ss.) a medida que, por causa quizá de un aumento de la población, la agricultura obtuviera un mayor peso que antes en el control y explotación de los recursos. Con todo, nada seguro se sabe al respecto.

Por otra parte, incluso durante el "orientalizante" los vestigios de actividades relacionadas con la minería y la metalurgia raramente se asocian a una especialización funcional de los espacios en zonas específicas, sino a una especialización por asentamientos que, no obstante, presentan en muchos casos claros indicios de una organización doméstica de los procesos de trabajo al vincularse los hallazgos, como en Cerro Salomón (Fig. 1), no con zonas concretas de producción sino con las mismas estructuras de habitación que conforman el poblado. En otras ocasiones asentamientos claramente caracterizados por su funcionalidad minero-metalúr- 


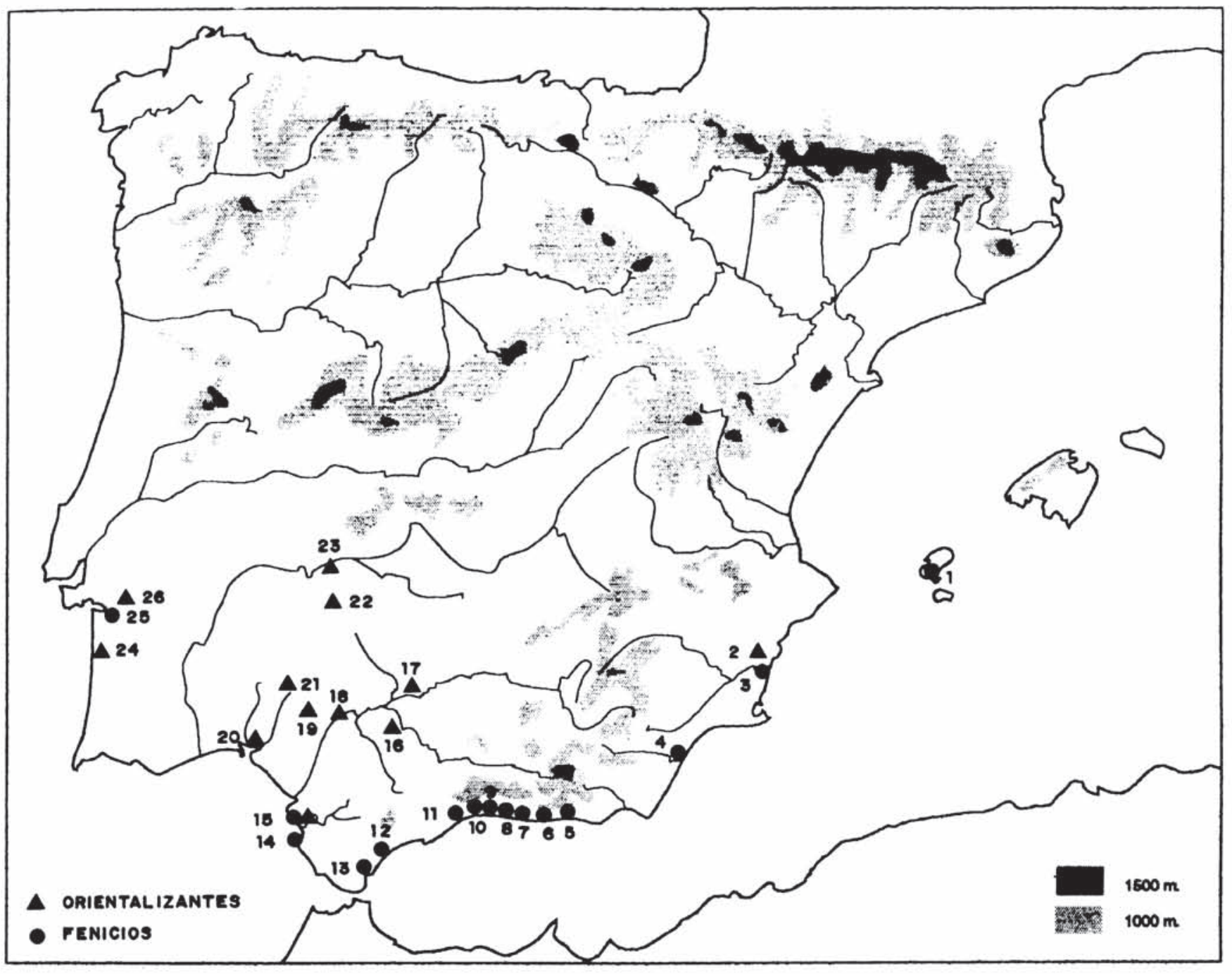

Fig. 1. Localización de los asentamientos fenicios y los yacimientos orientalizantes en la Península Ibérica:

\author{
1 Sa Caleta \\ 2 Peña Negra \\ 3 Guardamar \\ 4 Villaricos/Baria \\ 5 Adra/Abdera \\ 6 Almuñecar/Sex \\ 7 Chorreras \\ 8 Mezquitilla \\ 9 Toscanos \\ 10 Malaka \\ 11 Cerro del Villar \\ 12 Motilla \\ 13 Cerro del Prado
}
14 GADIR
15 Doña Blanca
16 Cruz del Negro
17 Setefilla
18 El Carambolo
19 Tejada
20 Huelva
21 Cerro Salomón
22 Cancho Roano
23 Medellín
24 Sines
25 Abul
26 Alcácer do Sal

gica presentan unos fuertes indicios de ocupación estacional (Ruiz Mata, 1989: 214 ss.) lo que no aboga precisamente en favor de una gran división del trabajo (Rowlands, 1971: 212 ss.). Más significativo aún me parece el que cuando esto no sucede así, como es el caso de Huelva o Tejada, todos los indicadores apuntan a una clara presencia del elemento colonial (Garrido, 1979: 39 ss.; Ruiz Mata, 1989: 229; Fernández Jurado, 1989: 353). Si en el registro arqueológico 
los vestigios de una especialización en los procesos de trabajo relacionados con la metalurgia se asocian a huellas inequívocas de la presencia fenicia, documentándose una organización doméstica de los procesos de trabajo o un ritmo de ocupación estacional cuando éstas faltan, difícilmente podremos concluir que el trabajo del metal constituye un exponente de elevada complejidad sociocultural en Tartessos.

Por lo que al volumen de los hallazgos respecta, resulta indicativo el que la metalistería tartésica, en contraste con el número de hallazgos en culturas europeas contemporáneas, haya sido calificada como un mito creado en gran parte por la erudición (Pellicer, 1989: 157) y que se haya señalado la sobrevaloración que se hace de estos objetos, normalmente descontextualizados, que han servido para crear un mito sobre Tartessos, heredado en gran medida de una lectura acrítica de las noticias recogidas por las fuentes literarias (Carrilero, 1993: 164). No deja de ser significativo que la mayor proporción de estos hallazgos se concentre en depósitos "utilitarios" o "votivos" que han sido interpretados como prueba del control ejercido localmente en la redistribución de los artefactos metálicos (Barceló, 1992: 267), de los que se ha resaltado también la escasez de útiles frente al predominio de armas y joyas (Ruiz-Gálvez, 1987: 256; Galán Domingo, 1993: 69). En el contexto de las relaciones sociales, la presencia de estos objetos metálicos y otros artefactos no productivos sólo constituye un indicador de la existencia de "bienes de prestigio" que pueden conseguirse mediante desplazamientos e intercambios con grupos lejanos, como pudieron ser los contactos atlánticos y mediterráneos (RuizGálvez, 1986). También pueden darse artesanos a tiempo parcial, ya que los ciclos agrícolas no ocupan todo el año, o especialistas, itinerantes o no, integrados de diversas formas en las relaciones de producción existentes (Rowlands, 1971: 213 ss.). Con todo, estos bienes de prestigio no son en si riqueza sino su imagen $(\mathrm{Ca}-$ rrilero, 1992a: 969; Wagner, 1991: 18), ya que la auténtica riqueza en estas sociedades la proporciona el control sobre los medios de producción mediante la redistribución y las alianzas matrimoniales (Meillassoux, 1972), al tratarse de unas condiciones en las que el efecto de la eficacia tecnológica hace innecesaria la apropiación de la tierra, resultando mucho más fructífero el control de la fuerza de trabajo y su pro- ducto. Es así, precisamente, que los bienes de prestigio adquieren su significado al poder ser utilizados como elementos de la dote para la adquisición de mujeres y regalos para sellar alianzas. Significativamente los objetos de prestigio representados en las estelas decoradas del Suroeste (Barceló, 1989; Celestino Pérez, 1991; Galán Domingo, 1993) son muy escasos en los hallazgos arqueológicos. ¿Se debe a que no se conocen las necrópolis de este periodo?. En dichas necrópolis se enterrarían estos símbolos de rango, dado que es preciso neutralizarlos finalmente para evitar una acumulación excesiva que pudiera desvirtuarlos, ya que en sociedades de esta índole la competencia social toma la forma de una acumulación de mujeres o una multiplicación de los aliados (Godelier, 1981: 92-3) que se obtienen gracias a estos bienes de prestigio en manos de los jefes de linaje. ¿Se debe esta ausencia de necrópolis no tanto a factores que inciden de forma aleatoria en la investigación arqueológica, cuanto al mismo carácter de las prácticas funerarias de aquellas poblaciones del Bronce Final, tal y como se viene defendiendo últimamente (Belén y Escacena, 1992b: 517; Barceló, 1992, 265)?. En cualquier caso, la presencia de depósitos, en los que tampoco aparecen las espadas y las fíbulas (Barceló, 1992: 266), contrasta con la ausencia de enterramientos de este periodo en los que supuestamente se hallarían tales ajuares metálicos, y puede interpretarse, en mi opinión, como prueba de las escasez de aquellas. De toda la cantidad de metal que circulaba entre la Península Ibérica, el llamado Círculo Atlántico y el Mediterráneo central durante este periodo sólo una pequeña parte se quedó en Tartessos a juzgar por la distribución y el volumen de los hallazgos. En este sentido se sugiere que, aunque se produjo un incremento durante el Bronce Final en el uso de metal procedente de la Península Ibérica y una disminución del centroeuropeo, "dado que no son muchos los testimonios de comercialización directa de la materia prima, es posible que ésta fuese conseguida por la refundición de objetos manufacturados en circulación" (Barceló, 1992: 268), idea que yo mismo he defendido (Wagner, 1983: 7) y que constituye una de las prácticas comunes en la obtención de metal en contextos poco especializados, donde el metalúrgico es aprovisionado por su "cliente" (Rowlands, 1971:211 y 212). Tampoco carece de significación que la mayor concentración de 
tales objetos en el Suroeste peninsular se produzca en un momento, finales del siglo VIII-siglo VII a.C., en que se detecta el auge del comercio fenicio, si bien más significativo aún resulta el descubrimiento de un núcleo metalúrgico en cuyos talleres se elaboraban útiles y armas del más puro estilo atlántico en un lugar tan periférico de Tartessos como la Peña Negra de Crevillente (Alicante), constatando allí, en un lugar claramente autóctono, además del comercio colonial desde la última mitad del siglo IX, la presencia misma de los artesanos fenicios (González Prats, 1991: 114).

¿Debemos interpretar todos aquellos intercambios como otro signo de la supuesta complejidad cultural? Cabe señalar que un comercio de largo alcance es perfectamente posible en una sociedad aldeana como la tartésica del Bronce Final. Dicho comercio, responsable seguramente de la introducción de objetos de origen europeo y mediterráneo, que suelen agruparse bajo la rúbrica de relaciones de tipo precolonial, no constituye tampoco una prueba de diversidad económica, especialización y complejidad sociocultural. Las gentes de las sociedades aldeanas pueden organizar, desde las posiciones de rango que presiden sus redes redistributivas, incursiones o expediciones hacia objetivos lejanos con el fin de procurarse objetos escasos u exóticos o conseguir botín de guerra. En ambos casos las dificultades estructurales son salvadas por la eficaz actuación del liderazgo centralizado al frente de la movilización ceremonial del esfuerzo que tales actividades requieren y del consenso para llevarlas a cabo. No obstante tampoco las expediciones lejanas son siempre necesarias; como señala Rowlands (1971: 11) "the trade of raw materials and finished products in metalworking need not therefore be the result of specialized trade contacts or longdistance trade routes, but a more diffuse pattern of interlocking trade networks may have existed dealing in numerous exchange commodities besides copper and tin and in which wider section of the population shared". Además, la evidencia arqueológica acumulada es de tal índole que puede ser utilizada de muy distinta manera, tanto para afirmar (Ruiz-Gálvez, 1986: 22 ss.) como para negar (Alvar, 1988: 436 ss.) un protagonismo de los autóctonos en estas navegaciones e intercambios.

Para aceptar que el desarrollo de sistemas de intercambio de gran alcance tuviera alguna in- cidencia notable en la aparición de una mayor complejidad socio-cultural habría que probar que ejercieron un impacto positivo en el incremento de la producción agrícola, favoreciendo el desarrollo de nuevas y más eficaces tecnologías, o que la alta calidad del trabajo en metal con que se comerciaba estimuló una demanda capaz de provocar finalmente un aumento de su producción que implicara una especialización acusada (Rowlands, 1971: 220). No es éste el caso, como se ha visto. Fundamentalmente se trataba de armas y otros artefactos que podemos considerar bienes de prestigio por lo que caen dentro de la esfera de las manifestaciones simbólicas y no en la de las actividades productivas, y su distribución, así como el hallazgo del taller de metalurgia "atlántica" en Crevillente sugiere una producción no localizada mayoritariamente en el Suroeste peninsular.

En aquellas comunidades aldeanas tartésicas, socialmente segmentadas en grupos de parentesco incipientemente jerarquizados que integran las unidades domésticas productivas, el conflicto y la explotación adquieren rasgos no clasistas, oponiendo a los grupos de edades y sexos (jóvenes productivos y adultos varones que controlan los linajes), como ocurre en este tipo de sociedades (Renfrew, 1984: 76). Esta es la primera esfera, la que corresponde al interior de los grupos de parentesco, en que se produce una explotación, limitada a la apropiación de una parte del trabajo de las mujeres y los más jóvenes por los adultos para convertirlo en bienes de prestigio. Otra oposición se establece entre linajes más débiles y aquellos otros más fuertes, segunda esfera en que se manifiesta el conflicto, si bien no se trata de una simple cuestión de tamaño sino de capacidad para intercambiar mujeres y concretar alianzas entre círculos jerarquizados de parientes debido al distinto coste de las mujeres de los diversos linajes (Friedman, 1977: 202 ss.), de mayor eficacia, en suma, para asegurar las condiciones de la reproducción social y mantener al mismo tiempo una posición de prestigio. Los círculos igualitarios de matrimonio se convierten así en una jerarquía de linajes que dan mujeres y linajes que reciben mujeres, produciéndose un reagrupamiento de los mismos en círculos de aliados capaces de pagar un "precio" similar por la novia, como consecuencia de que los linajes capaces de costear los ceremoniales más importantes, aquellos que detentan mayor rango 
en la jeraryuia social, son con quienes tienen más interés los demás en establecer alianzas. pero cuyas mujeres resultan más "caras". Finalmente, pero de forma paralela. el crecimiento de la población y su concentración en asentamientos estratégicos (Aubet, 1977-8: 89ss.; 1991: 36; Almagro y Gorbea, 1991: 98; Belén y Escacena, 1992a) provocaría la segmentación de muchos poblados con el subsiguiente aprovechamiento de nuevas tierras puestas en explotación con técnicas tradicionales (Carrilero, 1993: 165: Wagner, 1993a: 105), así como una incipiente competencia por los recursos, tercera esfera en que se produce el conflicto, lo que se puede advertir en el carácter de centro territorial, si bien a pequeña escala, que adquieren durante el Bronce Final los asentamientos más grandes, que se rodean de fortificaciones (Aubet, 1991: 37). En este ambiente, la jerarquización de los grupos de descendencia supedita unos linajes a otros apareciendo posiciones centralizadas de decisión no coactiva que denominamos jefaturas (Wagner, 1990). Pero las diferencias de autoridad y de prestigio no descansan aún en la acumulación de riqueza, o sea, en la apropiación del excedente, sino en la misma capacidad para aumentar la base productiva (incrementando el intercambio de mujeres) y los circuitos de redistribución (consiguiendo más aliados).

\section{PACTOS, ALIANZAS, MATRIMONIOS: EL MARCO SOCIAL Y POLÍTICO DE LOS INTERCAMBIOS COLONIALES}

Si bien se siguen utilizando conceptos como "mercado" aplicados a lugares como Huelva (Fernández Jurado, 1991: 172) en la interpretación de los lazos económicos entre autóctonos y colonizadores, el comercio, en un contexto como aquel, constituía una relación exclusiva con una parte externa específica, estableciéndose de antemano y con exactitud quién intercambia con quién. De esta manera eran las relaciones sociales y no los precios las que conectaban a los "compradores" con los "vendedores" (Sahlins, 1977: 319 ss.). Precios y mercado pudieron existir, pero no dirigían los procesos económicos. El intercambio a través del mercado sólo llega a dominar el proceso económico en la medida en que la tierra y los ali- mentos son movilizados por ese intercambio y allí donde la fuerza de trabajo se ha convertido en una mercancía que puede adquirirse libremente. Lo que el registro arqueológico sugiere es más bien un intercambio limitado a productos muy específicos y a sectores sociales restringidos (Aubet, 1984: 447). Y si bien es cierto que pudo haber existido competencia por el volumen del comercio externo, y que de hecho los sistemas internos de prestigio de las sociedades aldeanas jerarquizadas descansan a menudo sobre ella, no surge como una manipulación de los precios u otros procedimientos similares, sino que suele reposar sobre el aumento de los "socios" externos o del volumen del comercio ya existente (Sahlins, 1977: 322).

Por el contrario en una situación como la que, creo, caracterizó el encuentro y la "coexistencia" entre autóctonos y fenicios en el Suroeste de la Península, las actividades "económicas", "sociales" y "políticas" quedan entretejidas en un único marco de relaciones sociales que es el que posibilita la fluidez de los contactos e intercambios en el ámbito colonial. La presencia de santuarios, centrales, como el de Gadir o periféricos, como los de Cástulo y Alcàcer do Sal, los regalos, pactos, alianzas y matrimonios mixtos constituían otros tantos elementos que posibilitaban la vertebración de las relaciones entre unos y otros en un ambiente de marcado carácter colonial.

La funcionalidad polivalente de los santuarios (Grottanelli, 1981) ilustra la mezcla de intereses y actitudes a que me refería líneas arriba. Además de lugar de culto poseían un cometido en la organización y preservación de los intercambios comerciales, de los que se constituían en última instancia en garantes. Los santuarios facilitaban, con su misma presencia, la consecución de objetivos relacionados con el interés por establecer vínculos de amistad con la población autóctona (López Pardo, 1992: 96 ss.) Así, el santuario de Melkart en Gadir era expresión, al mismo tiempo, de la eficacia organizativa que caracterizaba al comercio fenicio, del carácter pacífico que se le quería imprimir a las relaciones que posibilitaban tal comercio, y nexo entre la periferia colonial y el centro, constituyendo un elemento clave en el trasvase de la riqueza que se extraía en el lejano Occidente. Por ello, si por un lado el templo de Melkart constituía un factor de integración que proporcionaba y garantizaba seguridad y fluidez en los 
intercambios (Aubet, 1987: 239 ss.), era también, por otra parte, el más claro exponente del desequilibrio de una política de pactos y alianzas que resultaban en la práctica desiguales, ya que la población autóctona no gozaba de las mismas condiciones técnicas y organizativas que preservaban los intereses de los colonizadores fenicios.

Los regalos cumplían así mismo una finalidad diversa. Representados en el registro arqueológico por los objetos de lujo "orientalizantes" que se difunden por los mismos lugares que antes los bienes de prestigio (armas, joyas, cerámicas) durante el Bronce Final (Barceló, 1992: 264), fueron utilizados por los colonizadores para procurarse el interés y la amistad de los "jefes redistribuidores" locales así como para penetrar en las redes de redistribución que quedaron conectadas, de este modo, con el comercio colonial. Mediante los regalos se establecieron vínculos de reciprocidad que más tarde se transformarán en dependencia.

Los matrimonios mixtos, que han sido considerados como vehículos de la aculturación (Whittaker, 1974: 74; Almagro Gorbea, 1983: 446), serían otro de los medios empleados en la articulación de vínculos sociales entre los colonizadores y los autóctonos, además de una necesidad inherente a muchos procesos de colonización en que se desplazan mayoritariamente los varones. La obtención de mujeres serviría para establecer relaciones de alianza y asegurar lazos de parentesco entre los colonizadores fenicios y las poblaciones autóctonas, mediante un sistema de intercambio de dones, similar al que posibilitaba el intercambio de manufacturas y materias primas (López Castro, 1995: 46). Sería tentador vislumbrar su huella arqueológica en algunos de los enterramientos presentes en las necrópolis tartésicas pero soy consciente de las dificultades de su interpretación. Aún así se puede decir que matrimonios mixtos y regalos constituían en realidad dos aspectos del mismo proceso cuyo objetivo consistía en crear las condiciones de una "coexistencia" que se refleja, por ejemplo, en la presencia de espacios funerarios fenicios en un contexto de enterramientos autóctonos, como en el túmulo 1 de la necrópolis de Las Cumbres, cerca de Cádiz (Ruiz Mata, 1991a: 94, 1989a: 213), lo que implica que los colonizadores habían sido admitidos dentro de la estructura social del grupo autóctono. Los procedimientos bien pudieron haber sido la adopción y/o el matrimonio.

\section{COMERCIO COLONIAL E INTERCAMBIO DESIGUAL: EL MARCO ECONÓMICO DE LAS TRANSACCIONES}

Constituye, cuanto menos, una posición ingenua considerar que las relaciones entre los colonizadores fenicios y las comunidades tartésicas se establecieron en un plano de igualdad. La ausencia de agresión manifiesta, de violencia directa como una característica de la presencia fenicia en Occidente señalada en ocasiones (Ruiz Mata, 1991a: 94) no da pie para afirmar el resultado mutuamente beneficioso de unas relaciones que se establecen entre miembros de dos formaciones sociales muy distintas. Quienes tal cosa argumentan olvidan, o desconocen, que el comercio colonial, como una de las formas en que se manifiesta el comercio lejano, constituye en realidad un modo de transferir una fracción del excedente desde una formación social a otra, lo que implica ganancia y un intercambio no equitativo (Wagner, 1993d: 16 ss) que también va más allá de las diferencias de "precios" ocasionadas por la "distancia" social (Bradley, 1985). Todo ello se materializa en las condiciones de desigualdad en que se realiza el tráfico comercial. Desigualdad en el ámbito de las capacidades técnicas y en aquel de la organización de los procesos productivos, que se manifestará en diferencias netas en los costes sociales de producción de lo que se intercambia. Desigualdad, en suma, que se concreta en un trasvase de riqueza en el que la parte económica, tecnológica y organizativamente más avanzada, en términos convencionales, consigue grandes cantidades de materias primas a cambio de un modesto volumen de manufacturas y objetos exóticos, como consecuencia precisamente de la diversa escala de valores en uso en ambos polos del sistema de intercambios (cfr: López Pardo, 1987: 410). Por ello supone un error considerar que para que las grandes inversiones en materia de comercio a larga distancia resultasen rentables era necesario un intercambio a gran escala (Barceló, 1992: 262). En realidad no se trata tanto de una cuestión cuantitativa como cualitativa, ya que las ganancias no proceden tanto del volumen de los intercambios cuanto de las 
diferencias en costes sociales de producción de los productos que se intercambian. Claro está que había beneficios, pero éstos estaban basados en la diferencia de valores subjetivos (utilidades sociales) apreciados desigualmente en dos sociedades distintas que intercambiaban productos cuyos costes sociales de producción no compartían, y no deben confundirse con la ganancia de capital comercial (Amín, 1986: 24). Había otras formas de asegurar las inversiones como eran eliminar costes de transporte y almacenamiento aproximando lo más posible los centros de producción a los lugares de intercambio, sobre todo cuando el volumen de las mercancías así como su valor de uso implica cargamentos voluminosos (López Pardo, 1987: 342 ss.; Wagner, 1993b: 86). Ello explica, de paso, la proliferación de centros fenicios sobre la costa del litoral mediterráneo andaluz en un patrón de asentamiento que se caracteriza por su extraordinaria densidad y con muestras evidentes de actividades económicas diversificadas (Wagner, 1988: 426 ss.). Por supuesto todo ello no supone desinterés por parte de los colonizadores en dinamizar los intercambios, pero tal dinamización afecta no sólo al volumen, sino a la intensidad y a la penetración en nuevos contextos autóctonos, ampliando de esta forma el alcance de las relaciones de índole colonial. De todo ello constituyen claros indicadores la presencia fenicia en lugares como la Peña Negra de Crevillente (González Prats, 1986) y la existencia de asentamientos coloniales como el de Guardamar, junto a la desembocadura del río Segura (González Prats, 1991: 113), el de Sa Caleta en Ibiza, con sus claras evidencias de una procedencia del "Círculo fenicio del Estrecho" (Ramón, 1991), así como el recientemente descubierto de Abul en Alcácer do Sal (Mayet et alii, 1993). Debe quedar igualmente claro que la parte que obtiene el beneficio, en este caso los colonizadores fenicios, no se está tan sólo aprovechando de las mencionadas diferencias en costes sociales de producción, sino que, precisamente por ello, el intercambio desigual encubre una realidad de sobre-explotación del trabajo (Meillassoux, 1977: 131 ss.), que se articula en la transferencia de riqueza entre sectores económicos que funcionan sobre la base de relaciones de producción diferentes. En este contexto el modo de producción propio de las comunidades autóctonas, al entrar en contacto con el modo de producción de los colonos orientales queda domi- nado por él y sometido a un proceso de transformación. La contradicción característica de tal transformación, la que realmente la define, es aquella que toma su entidad en las relaciones económicas que se establecen entre el modo de producción local y el modo de producción dominante, en las que éste preserva a aquél para explotarle, como modo de organización social que produce valor en beneficio del colonialismo, y al mismo tiempo lo destruye al ir privándole, mediante la explotación, de los medios que aseguran su reproducción.

El problema, por tanto, es más amplio y complejo que una simple política de pactos y alianzas (desiguales) con las élites locales. Por una parte el contacto con los colonizadores incidió acentuando la diversificación de las prácticas económicas (Wagner, 1983: 10) al propiciar una demanda externa de minerales que creó el incentivo para que los jefes situados en el centro de los sistemas redistributivos locales movilizaran la mano de obra necesaria para la intensificación de las tareas de extracción minera. La experiencia acumulada procedente de otros entornos nos muestra que la capacidad intensificadora y la eficacia para movilizar mano de obra de las personas situadas en el centro de los sistemas redistributivos es sumamente operativa (Sahlins, 1972: 148 ss.; 1979280 ss.; Renfrew, 1984: 74), por lo que no es necesario recurrir a imaginar relaciones sociales de dependencia de tipo servil o esclavistas, propias de sociedades estratificadas.

Por supuesto, las élites locales (Aubet, 1984), en pleno proceso de formación, respondieron positivamente a los requerimientos de la demanda de los colonizadores fenicios. En un sistema de rango y jerarquía, como aquél, el comercio con los colonizadores les proporcionaba la capacidad no sólo de adquirir nuevos bienes de prestigio que contribuían a reproducir las relaciones sociales que les habían encumbrado sino que mediante su adquisición se apropiaban, al movilizar la fuerza de trabajo necesaria para dar respuesta a los requerimientos de los colonizadores, de una parte del excedente en forma de trabajo extra (cfr: Gudeman, 1981: 256). No fue por tanto el trabajo artesanal el que propició las condiciones necesarias para que la élite se apropiara del excedente (Barceló, 1992: 261 y 270), y no poseemos tampoco claros indicios de un fuerte desarrollo de la especialización durante el 
orientalizante, sino la redistribución asimétrica o desigual de lo obtenido a partir del trabajo extra que era capaz de movilizar desde su control de la red redistributiva. Por eso creo erróneo considerar que la desigualdad intrínseca al intercambio radicara en que la naturaleza del beneficio que cada parte perseguía era distinta, obteniendo los fenicios "dinero", valor de cambio, y las élites tartésicas prestigio, reconocimiento y poder (López Castro, 1995: 52). Las élites locales en Tartessos también se enriquecieron con el comercio con los colonizadores fenicios, pero el proceso y la forma en que se produjo tal enriquecimiento fueron distintos. Por un lado, la riqueza "orientalizante" en manos de las élites emergentes diversificó su procedencia al dejar de ser proporcionada en exclusiva por el control ejercido sobre los medios de producción a través de las alianzas y el intercambio de mujeres, pero al mismo tiempo, y por ello, las élites quedaron supeditadas a su colaboración en el mantenimiento del comercio colonial. Tales intercambios, al proporcionar una forma de "realizar" el excedente (Terray, 1977: 149 ss.) controlado por las élites, desempeñaba un importante papel en el sostenimiento del sistema económico y las élites autóctonas pasaron a depender cada vez en mayor medida del comercio con los colonizadores para poder seguir practicando en el seno de sus comunidades una redistribución asimétrica que producía beneficios económicos, amén de sociopolíticos, permitiéndoles apropiarse del excedente en forma del trabajo invertido en la obtención del mineral (Wagner, 1991: 21, 1993: 106). Quizá por ello, al produ-cirse un aumento neto del fondo de poder sobre el que se situaban, actuaron con un alcance cada vez más amplio, tal y como la distribución de los objetos orientalizantes en Portugal o Extremadura sugiere, introduciendo de este modo una serie de relaciones centro/periferia que esbozan un sistema formado por círculos económicos concéntricos y jerarquizados, lo que permitió finalmente a las élites tartésicas acceder a recursos situados fuera de los territorios que directamente controlaban, de forma más regular que mediante los anteriores intercambios esporádicos, asegurando de esta forma el incremento del volumen de materias primas y recursos que permitiera perpetuar y reproducir su rol dominante en Tartessos (Aubet, 1991: 40-1).
Seguramente los propios fenicios se encontraban interesados en ello, ya que de esta forma se reproducían al mismo tiempo las condiciones que dinamizaban el comercio colonial, y es en este contexto, al margen de la interpretación específica de su carácter como palacio/santuario etc, que puede hallar su significación Cancho Roano (López Pardo, 1990; Celestino Pérez y Jiménez Avila, 1993: 154 ss.) como un elemento inserto en una estrategia colonial que persigue ampliar el horizonte de los intercambios.

Pero al mismo tiempo que las élites se consolidaban era necesario preservar las redes redistributivas que controlaban, lo que les permitía, en suma, movilizar la fuerza de trabajo necesaria para las tareas minero-metalúrgicas. Aunque prácticamente carecemos de información al respecto, la pervivencia de las prácticas económicas tradicionales adquiere un valor significativo. Tal pervivencia se advierte en la continuidad del patrón de asentamiento (Amores y Rodriguez Temiño, 1984; cfr: Barceló, 1992: 263), en la escasa renovación tecnológica que supuso la tardía incorporación del utillaje de hierro, así como en un desarrollo artesanal lento que se percibe en hechos tales como el más de siglo y medio que fueron necesarios para que se generalizara la cerámica a torno.

Tal es la dinámica que explica la continuidad del modo de producción doméstico en Tartessos (Wagner, 1993a: 110 ss.) así como los cambios que al término del periodo "orientalizante" (fines del siglo VI a.C.) modificaron las relaciones entre los colonizadores fenicios y la población autóctona. Tales cambios fueron, en última instancia, consecuencia de la tensión que introdujo la aparición de formas simples de economía política sobre las estructuras tradicionales en un momento en que comenzaba a producirse el agotamiento de los recursos bajo formas de dependencia tecnológica colonial. La desarticulación de la formación social tartésica, que desapareció finalmente para dar paso a la posterior formación iberoturdetana, su desestructuración, fue en definitiva, y por más que desconozcamos los detalles, la consecuencia histórica de la dinámica contradictoria del proceso por el cual los colonizadores fenicios se beneficiaban de la sobre-explotación del trabajo de las poblaciones del extremo occidental mediterráneo. 


\section{CAMBIO CULTURAL Y CAMBIO SOCIAL: ALCANCE Y SIGNIFICADO DE LA ACULTURACIÓN "ORIENTA LIZANTE"}

Manejando los mismos datos procedentes del registro arqueológico una parte de la investigación (Almagro Gorbea, 1991a: 240; Fernández Jurado, 1991: 171 ss., 359; Blázquez, 1991: 35 ss.; Ruiz Mata y Pérez, 1989: 293) realiza una interpretación de las consecuencias del contacto intercultural durante el orientalizante en términos de lo que describen como una aculturación rápida e intensa, así como bastante generalizada, de las poblaciones del Suroeste peninsular, mientras que otros investigadores interpretan los resultados de dicho contacto como una aculturación mucho más lenta, parcial y selectiva, un fenómeno que afectó sobre todo a las élites (Aubet, 1977-8: 98 ss., Wagner, 1986b, 1993a: 107; Tsirkin, 1981: 417 ss.), permaneciendo el resto de la población al margen o bajo el "impacto" de una aculturación ciertamente superficial. Tales discrepancias ponen una vez más de manifiesto como los datos que poseemos no bastan por sí solos para explicar los procesos por lo que se hace necesario su estudio dentro de un modelo elaborado a partir de unas proposiciones teóricas previas.

En los estudios sobre Tartessos, y sobre la Protohistoria de la Península Ibérica en general, no se suele diferenciar entre aculturación y "difusión cultural", entre aculturación impuesta o espontánea, o entre "asimilación e integración" (Wagner, 1993c) y se tiende a percibir el resultado de la interacción cultural como un conjunto de fenómenos positivos, y por consiguiente "necesarios", en tanto que generan "progreso" histórico o mejoran, mediante las innovaciones que introducen, las condiciones en que se desenvuelven las comunidades que reciben su impacto. Más raramente se advierte que la aculturación puede obrar destructivamente, como la evidencia procedente de otros entornos ha señalado (Wachtel, 1978: 154; Murphy y Steward, 1981: 219 ss.; Burke, 1987: 127), dando lugar a fenómenos de rechazo y supervivencia cultural, o contraculturación, que se pueden manifestar de muy diversas formas (Gruzinski y Rouveret, 1976: 199-204). En otras ocasiones la aculturación puede ocasionar una situación que se conoce como "pluralismo estabilizado", allí donde las culturas implicadas se atienen a un mutuo acomodo en una misma área en una relación asimétrica que les permite persistir respectivamente en su línea distintiva (Morel, 1984: 132 ss.; cfr: Chapa, e.p.). Tampoco se suele tener presente que la aculturación es un proceso dinámico, con diferentes fases y niveles por lo que sus resultados diferirán dependiendo del momento en que tal proceso se encuentre (Alvar. 1990), y que por tanto se trata de algo más complejo que las simplificaciones que a menudo se hacen. También se confunden otras veces cambio cultural y cambio social. Ello es en gran parte consecuencia de la mayoritaria adscripción de los investigadores a la arqueología histórico-cultural en la que el difusionismo constituye la explicación por excelencia de las distintas secuencias históricas (López Castro, 1992: 48 ss.; 1993)

Aunque, en general, los cambios culturales se relacionan estrechamente con los sociales, a los que pueden preceder o de los que, en algunas ocasiones, pueden actuar como desencadenantes, es preciso establecer una distinción nítida entre ambos, en tanto que afectan a distintos tipos de prácticas y conductas. El cambio cultural implica alteraciones en ideas y creencias, afectando por tanto a las actitudes y las costumbres, mientras que el cambio social entraña transformaciones en la estructura de las relaciones sociales, de sus cometidos y funciones. Creo, en contra de una idea bastante extendida, que la población de Tartessos se vio a la larga afectada por un cambio social como consecuencia de la desarticulación de las relaciones de parentesco que fueron sustituidas por formas de dependencia "clientelar" (Wagner, 1993a: 111), en las que la apropiación de la riqueza no entrañaba la de la tierra sino la del trabajo extra no agrícola, tal y como se percibe en las escasas modificaciones del patrón de asentamiento en contraste con el proceso que caracterizará el ámbito ibérico (Ruiz y Molinos, 1993: 262 ss.; Santacana, 1995: 151 ss.), lo que en último término no fue sino el resultado de la tensión provocada por la explotación colonial sobre las formas tradicionales de organización social. Pero el cambio cultural incidió poco en ella, y cuando lo hizo fue mediante la reinterpretación de las innovaciones que adquirían de esta manera sentido acorde a las pautas, ideas, valores y costumbres propios de la tradición local. 
Como ya he expuesto mis argumentos en otra parte (Wagner, 1986b, 1991, 1993a y 1993d) no insistiré nuevamente sobre ello, pero sí diré que en consonancia con el modelo que defiendo a lo largo de estas páginas, la aculturación orientalizante constituyó el resultado de una estrategia colonial no violenta, en términos convencionales, de control que reposaba sobre la subordinación económica de las élites tartésicas, lo que hacía posible su supeditación a la jerarquía colonial en el proceso de toma de decisiones. Fue resultado, por tanto, del marco económico y político en que se establecieron los intercambios, y sus consecuencias no parecen tan beneficiosas como comunmente se pretende, o en todo caso cabe preguntarse a quién beneficiaron más y a quienes menos los cambios producidos durante dicho período. Las fuerzas productivas no parecen haberse desarrollado especialmente, pues aún admitiendo que la mayoría de los objetos "orientalizantes" que aparecen en las tumbas de carácter "principesco" (Ruiz Delgado, 1989) hubieran sido manufacturados por artesanos autóctonos que hubieran adquirido sus habilidades de los colonizadores, lo que no es seguro (Belén, 1994: 500), dicha tecnología, al no participar en las tareas productivas sino en otras de carácter simbólico no constituye sino un exponente de una economía de prestigio y no documenta ningún desarrollo de aquellas (Carrilero, 1992b: 131 ss.). La especialización artesanal no parece haber adquirido tampoco un desarrollo notable como consecuencia, precisamente, de la dependencia tecnológica que implicaba el intercambio desigual. Dependencia que se aprecia en la especialización colonial que utilizaba la fuerza de trabajo autóctona en la extracción del mineral y en los niveles menos complejos de los procesos de trabajo metalúrgicos, mientras que reservaba las fases que implican una mayor complejidad y por tanto conocimientos más especializados a los colonizadores, tal y como se observa en el registro arqueólogico, ya que siempre que constatamos una especialización acusada en el seno de las actividades metalúrgicas, constatamos simultáneamente la presencia de los colonizadores en el mismo lugar, como ya dijimos que ocurre en Huelva o Tejada. Tal es la razón por la que probablemente cesa la fabricación de bronces orientalizantes en el Suroeste desde finales del siglo VI, momento en que culminará la desestructuración de la formación social tartésica.

Así, la dinámica de cambio, sometida a la tensión inherente al contacto colonial, se plasmó en un cambio social paulatino en el que la aculturación no tuvo demasiado protagonismo. A este respecto la asimilación de los objetos no conlleva necesariamente, como a veces se piensa, la de "las ideas conexas" ya que es preciso diferenciar entre forma (categorías, modelos) y contenido (información cultural) (Wagner, 1993c: 446) y la aceptación de la una no implica siempre la del otro, sino que es posible, sobre todo en situaciones de aculturación no impuesta como la que nos concierne, adoptar una forma cultural externa y dotarla de un contenido propio. Si, como creo, las élites tartésicas surgieron a partir de posiciones sociales de prestigio (liderazgo centralizado) gracias a la oportunidad que el comercio colonial les brindó para apropiarse del excedente en forma de trabajo extra invertido en las actividades minero-metalúrgicas, y no sobre la base de una apropiación real de la tierra que no es posible constatar en parte alguna, entonces las distorsiones en el comercio que se detectan hacia finales del orientalizante, hubieron de afectarlas negativamente. De ahí, seguramente su interés en dinamizar un sistema propio de intercambios entre el centro (el Suroeste) y una periferia (Extremadura) que acusa ahora el impacto tardío de los contactos orientalizantes (Aubet, 1991: 40) como una alternativa al comercio colonial que las había encumbrado y del que tan estrechamente dependían.

En su conjunto la formación social tartésica sufrió a la larga las consecuencias de una "desestructuración" (Alvar, 1990: 23 ss.), cuyo alcance real no estamos aún en condiciones de precisar, en la que la desigualdad y la dependencia tecnológica, siempre a favor de los colonizadores, desempeñaron un importante papel. Por contra, los supuestos avances de la más compleja cultura colonial (como la escritura y la tecnología del hierro), a los que se responsabiliza a menudo del "progreso" de las comunidades tartésicas durante el "orientalizante", tardaron en incorporarse a las prácticas autóctonas o lo hicieron muy parcialmente (Wagner, 1986b: 134 ss., 1991b), como corresponde a un modelo colonial de "intercambio desigual", y cuando novedades formales alóctonas fueron aceptadas, los mecanismos de integración de- 
terminaron casi siempre una aculturación muy superficial.

Por todas estas consideraciones no me parecen convincentes los argumentos que abogan por una fuerte aculturación, perceptible incluso en el marco de las creencias y prácticas funerarias, a partir de contactos predominantemente comerciales y realizados fundamentalmente desde los centros coloniales de la costa. Tal vez esto pueda ser posible en un sitio tan próximo a la colonia fenicia de Gadir como Torre de Doña Blanca, con indicios, además, de coexistencia estrecha entre colonizadores y autóctonos (Ruiz Mata, 1993), pero resulta menos verosímil a medida que penetramos hacia el interior. En todo caso quienes defienden la aculturación rápida e intensa dejan sin explicar el porqué ha de producirse la atracción cultural, puesto que dan por supuesto que ésta era inevitable, pero como he dicho la evidencia empírica procedente de otros contextos muestra que esto no siempre es así. Tampoco se explica cómo es posible que una sociedad, la autóctona, adopte con tanta facilidad rituales funerarios ajenos mientras que en otras ocasiones, y en relación a actividades que implicarían niveles mucho más superficiales de aculturación, se muestre mucho más conservadora discriminando, por ejemplo, qué tipo de recipientes cerámicos se imitan y cuáles no.

En mi opinión existe una mejor manera de comprender la presencia de tumbas y rituales de procedencia fenicia en el seno de un ambiente marcadamente autóctono, lo que pasa por admitir la presencia fenicia en el interior e incluso cierto grado de mestizaje. Parto para ello de la consideración de que es difícil admitir un fuerte protagonismo de las relaciones comerciales en los cambios culturales supuestamente detectados. En ninguna parte el comercio, por intenso que sea, actúa como factor que propicie la aculturación (Wagner, e.p.), siendo en todo caso responsable de la aparición de fenómenos de difusión cultural que no deben confundirse con aquélla. Por ello la presencia de tumbas y rituales fenicios en el interior ha de interpretarse de una manera distinta a como se ha venido haciendo hasta ahora por lo que, si las gentes que se entierran siguiendo costumbres fenicias en el Valle del Guadalquivir o Extremadura no eran fenicios sino autóctonos profundamente aculturados, debemos sospechar la presencia cercana y permanente de aquéllos para que tal aculturación fuera posible por lo que se impone su verificación en el registro arqueológico. Pero puesto que, debido al peso de las concepciones académicas imperantes (López Castro, 1993; Belén, 1994: 501 y 506), se parte de la consideración previa de que no es posible encontrar fenicios muy alejados de la costa, difícilmente, si antes no nos desprendemos de aquel, podremos verificar su presencia, puesto que de inmediato lo interpretaremos como consecuencia de algún tipo de aculturación.

\section{LOS FENICIOS EN LA COSTA Y EN EL INTERIOR}

La proliferación de asentamientos fenicios en la costa se corresponde con una proliferación de datos que pueden ser leídos como testimonios de una presencia fenicia en el interior (Belén, 1994: 506) a poco que nos libremos del tópico que convierte a los fenicios en mercaderes exclusivamente asentados en el litoral. Cada vez más, por otra parte, la evidencia procedente de otros lugares del Mediterráneo muestra cómo en realidad esto no siempre fue así (cfr: Gómez Bellard, 1991: 52, Manfredi, 1994: 214). Si las estructuras y las prácticas funerarias que advertimos en lugares como la Cruz del Negro (Carmona, Sevilla), con su réplica arqueológica en el sector arcaico de la necrópolis ibicenca del Puig des Molins (Goméz Bellard, 1990) se encontraran en algún lugar de la costa probablemente no tendríamos tanta dificultad para admitir su carácter fenicio. Al menos no lo tenemos en sitios como la necrópolis de Las Cumbres correspondiente al Castillo de Doña Blanca (Ruiz Mata, 1989) o en la de Villaricos (Astruc, 1951, Chapa, e.p.) donde también conviven prácticas funerarias propias de los autóctonos y de los colonizadores. Cabe preguntarse qué tipo de razón metodológica nos obliga a pensar que la tumba fenicia encontrada en un contexto funerario mixto, que por lo demás no es exclusivo de la Península, corresponde a la sepultura de un fenicio cuando se halla en la costa y a la de un autóctono profundamente aculturado cuando la hallamos en el interior. Más aún, cabe preguntarse qué clase de criterio metodológico nos induce a pensar que el comercio con los colonizadores establecidos en la costa, por intenso y asiduo que lo consideremos, es la relación responsable de tal aculturación expresada en el terreno funerario, máxime si tenemos 
en cuenta que las tumbas fenicias de este tipo no constituyen precisamente, aunque las conozcamos en Ibiza y otros lugares fenicios del Mediterráneo, la forma de enterramiento predominante en las necrópolis coloniales del litoral, como Trayamar, Almuñecar o la misma Cádiz (Wagner, 1993b: 89 ss.). Dado que no encuentro respuesta apropiada, me inclino a considerar que en realidad, y a despecho de nuestros tópicos más enraizados, las tumbas fenicias que encontramos en el interior corresponden a sepulturas de fenicios en los que, por supuesto, se puede percibir también el impacto de la aculturación de procedencia autóctona (Belén, 1994: 511).

Una cuestión bien distinta es que podamos proporcionar una explicación medianamente convincente que nos permita contextualizar su presencia en lugares que no siempre aparecen vinculados de forma clara con el comercio orientalizante. La cosa, por supuesto, no resulta sencilla. Una primera dificultad consiste en hallar formas que nos permitan conceptualizar la situación, en su relación con la tierra, de tales fenicios, al menos si consideramos que probablemente no todos fueron comerciantes y artesanos. En este sentido las fuentes literarias pueden echarnos una mano cuando leemos que Argantonio ofreció a los focenses la posibilidad de establecerse en su "reino" (Herodoto, I, 163, 3) lo que lleva a pensar en formas de implantación o presencia territorial que no entrañen necesariamente tensión o violencia. En cualquier caso es el mismo tipo de problema que debemos plantearnos en relación con la ubicación de los asentamientos fenicios en los territorios de la costa. Otra dificultad procede de la conveniencia o no de admitir una penetración agrícola fenicia a lo largo del valle del Guadalquivir, dificultad que se percibe más notoria si nos empeñamos en concebir tal empresa de forma aislada de la realidad que debía conformarla. Pero, si nos es posible asimilar la idea de una coexistencia entre autóctonos y colonizadores fenicios en un lugar de la costa como Doña Blanca o más al interior como en la Peña Negra ¿qué tipo de prevención nos impide imaginar una situación igual, digamos, en los Alcores de Carmona?. Aún asumiendo plenamente la crítica de Carrilero (1993: 178 ss.) sobre nuestra interpretación de tales necrópolis -aún no se habían producido las recientes excavaciones en Cruz del Negro- y entendiendo que en ellas conviven una multiplicidad de formas y ritos en los que, además, el prestigio no aparece aún claramente definido, ¿sobre qué descansa entonces la imposibilidad de pensar que las tumbas fenicias que aparecen en tales lugares correspondan efectivamente a fenicios allí enterrados?. La solución que se propone como alternativa tampoco explica porqué determinados grupos de la población tartésica escogen las formas y el ritual fenicio y otros no, y al convertirlo en una consecuencia del cambio social producido durante el "orientalizante", la transición entre las formas antiguas y las nuevas en la que aún no está nada plenamente definido, lo que explicaría la variabilidad de rituales y de las diversas manifestaciones de prestigio con ellos asociadas, tampoco se deja claro de qué manera el cambio cultural influye en el cambio social.

En mi opinión, el cambio social operado en Tartessos durante el orientalizante no es incompatible con la presencia de colonizadores agrícolas en el interior, lo que aclararía de paso la toponímia de origen semita en el mediodía peninsular que no creo pueda achacarse a la ulterior etapa de influencia cartaginesa (Wagner, 1993b: 82 ss., 1994), como consecuencia de una estrategia mediante la cual "el centro" (las ciudades de Fenicia) logran atenuar la tensión y los conflictos desatados, en último término, por las invasiones asirias, transfiriendo una parte de la población rural desarraigada a la periferia (Wagner y Alvar, 1989; Wagner, 1993d: 33). Así, la explo-tación a que el centro somete a la periferia no se manifiesta sólo en el trasvase de riqueza desde ésta hacia aquel sino también en el traslado del "sobrante" de su población hacia aquella. Ya que estamos trabajando en una reelaboración de nuestra hipótesis sobre "la colonización agrícola" que publicaremos próximamente no trataré más el tema aquí por el momento. No obstante me gustaría advertir que no es necesario pensar en una migración de grandes proporciones, sino en grupos distribuidos aquí y allá en los diversos lugares en que los fenicios se encuentran asentados en el Mediterráneo, lo que también explica porque crecen todos sus asentamientos coloniales en el mismo periodo. En el Valle del Guadalquivir, y en algunos otros lugares, su presencia posibilitó una convivencia más estrecha con los autóctonos, posiblemente hasta un mestizaje, fenómeno que no es desconocido en el marco de la expansión fenicia (Whittaker, 1974: 70; López 
Castro, 1995: 45 ss.) así como la asimilación de influencias recíprocas que confieren su peculiar complejidad al registro arqueológico.

\section{BIBLIOGRAFÍA}

Alvar. J. (1980): “El comercio del estaño atlántico durante el periodo orientalizante". Memorias de Historia Antigua, IV: 43-49.

- (1988): “La precolonización y el tráfico marítimo fenicio por el Estrecho". Congreso Internacional: El Estrecho de Gibraltar (Ceuta, 1987). Madrid, 1: 161-176.

- (1990): "El contacto cultural en los procesos de cambio". Gerión, 8: 11-27.

- (1994): "Reflexiones sobre el concepto cultural de Tarteso". En J. Mangas y J. Alvar (eds.): Homenaje a José María Blázquez, II. Ed. Clásicas. Madrid: 37-43.

Alvar. J. y WaGner, C.G. (1988): "La actividad agrícola en la economía fenicia de la Península Ibérica". Gerión, 6: 169-185.

Almagro Gorbea, M. (1983): "Colonizzacione e acculturazione nella Penisola Iberica". Forme di conttato e processi di transformazione nelle societá antich. Pisa-Roma: 429-461.

- (1991)a: "La necrópolis de Medellín". IV Jornadas de Arqueología Fenicio-púnica, (Ibiza, 1989). Trabajos del Museo Arqueológico de Ibiza, 24: 233-252.

- (1991)b: "El periodo orientalizante en Extremadura". "La cultura tartésica en Extremadura" (Mérida, 1990). Cuadernos Emeritenses, 2: 87-125.

Amin, S. (1986): El desarrollo desigual. Planeta-Agostini. Barcelona.

Amores, F. y Temiño. I.R. (1984): “La implantación durante el Bronce Final y el Periodo Orientalizante en la región de Carmona". Arqueología Espacial, 4: 97-115.

Astruc, M. (1951): La necrópolis de Villaricos. Informes y Memorias de la Comisaría General de Excavaciones Arqueológicas, 25. Madrid

AubEt, M" E. (1977-8): "Algunas cuestiones en torno al periodo orientalizante en Tartessos". Pyrenae, 13-14: 81-107.

- (1984): "La aristocracia tartésica durante el periodo orientalizante". Opvs, III: 445-468.

- (1987): Tiro y las colonias fenicias de Occidente. Bellaterra. Barcelona.

- (1989) (coord.): Tartessos. Arqueología protohistórica del Bajo Guadalquivir. AUSA. Sabadell.

- (1991): "El impacto fenicio en Tartessos: las esferas de interacción". "La cultura tartésica en Extremadura" (Mérida, 1990). Cuadernos Emeritenses, 2: 29-44.

BARCElo, A. (1989): "Las estelas decoradas del Sudoeste de la Península Ibérica". En $\mathbf{M}^{a}$ E. Aubet (coord.): 189-205.

- (1992): "Una interpretación socioeconómica del Bronce Final en el Sudoeste de la Península Ibérica". Trabajos de Prehistoria, 49: 259-275.
Błten. M. (1986): "Importaciones fenicias en Andalucía Occidental". Aula Orientalis, IV: 263-277.

- (1994): "Fenicios en Andalucía occidental. Diez años de investigación (1980-1990)". Hispania Antiqua, XVIII: 495-518.

Beien, M. y Escacena, J.L. (1992)a: "Las comunidades prerromanas de Andalucía Occidental”. En M. Almagro Gorbea y G. Ruíz Zapatero (eds): "Paleoetnología de la Peninsula Ibérica”. Complutum, 2-3: 65-87.

- (1992b)b: "Las necrópolis ibéricas de Andalucía occidental". En J. Blanquez y V. Antona (coord.): Congreso de arqueologia Ibérica: las necrópolis (Madrid. 1991). Univ. Autónoma. Madrid: 509-530.

Bendala Galan, M.: Rodrígilez. Termiño, I. y Núnez, E. (1994): "Una nueva estela de guerrero tartésica de la provincia de Córdoba”. En J. Mangas y J. Alvar (eds.): Homenaje a José María Blázquez, II. Ed. Clásicas. Madrid: 59-70.

BLAzquez. J.M. (1991): "Panorama general del desarrollo histórico de la cultura tartésica desde finales de la Edad del Bronce, s. VIII a.C., hasta los orígenes de las culturas turdetana e ibérica. Los influjos fenicios". Rivista di Studi Fenici, XIX: 33-48.

Bradlfy, R. (1985): "Exchange and social distance. The structure of Bronze Artifact distributions". Man (N.S.). 17, 1: 108-122.

Burke, P. (1987): Sociología e Historia. Alianza. Madrid.

CARrilero. M. (1992)a: El fenómeno campaniforme en el Sureste de la Península Ibérica. Univ. de Granada. Granada. Tesis doctoral microfichada.

- (1992)b: "El proceso de transformación de las sociedades indígenas de la periferia tartésica". La colonización fenicia en el sur de la Península Ibérica. 100 años de Investigación (Almería, 1990). Instituto de Estudios Almerienses: 117-142.

- (1993) "Discusión sobre la formación social tartésica". En J. Alvar y J.M. Blázquez (eds.): Los enigmas de Tarteso. Cátedra. Madrid: 163-185.

Celestino Pérez. S.C. (1991): "Las estelas decoradas del S.O peninsular". La cultura tartésica en Extremadura (Mérida, 1990). Cuadernos Emeritenses, 2: 47-61.

Celestino Pérez, S.C. y Jiménez de Ávila, F.J. (1993): $E l$ palacio-santuario de Cancho Roano, IV El sector norte. Gil Santacruz. Badajoz.

CRUz Andreotti. G. (1991): Tartessos como problema historiográfico: el espacio mítico y geográfico del Occidente Mediterráneo en las fuentes arcaicas y clásicas griegas. Univ. de Málaga. Tesis dotoral microfichada.

Chapa Brunet, T. (e.p.): "Models of Interaction between punic colonies and Iberian land: the funerary evidence". En L. Prados, A. Gilman y M. Balmuth (eds.): Iberian/Sardinian Colloquium (Tufts. University, Boston, 1991). Monographs in Mediterranean Archaeology.

De Hoz, J. (1989): "Las fuentes escritas sobre Tartessos". En MaE. Aubet (coord.): 25-43.

Fernández JuRAdo, J. (1989): "La orientalización de Huelva". En MaE. Aubet (cord.): 339-373.

- (1991) "Influencia fenicia en la arquitectura tartésica". III Jornadas de Arqueología Fenicio-púnica (Ibiza, 
198x). Trabajos del Museo Arqueológico de Ibiza, 24: 169-206.

FRIIIJMAN. J. (1977): "Tribus, estados y transformaciones". En M. Bloch (ed.): Análisis marxistas y antropología social. Anagrama. Barcelona: 191-240.

Gal.An Domingio, E. (1993): “Estelas, paisaje y territorio en el Bronce Final del Suroeste de la Peninsula Ibérica". Complutum, 3. Madrid.

GARRIDO, J.P. (1979): “Mundo indígena y orientalizante en la región del Tinto-Odiel". Archivo Español de Arqueologia, 52: 39-48.

- (1983): "Presencia fenicia en el área atlántica andaluza: la necrópolis orientalizante de La Joya (Huelva)". I Congresso Internazionale di Studi Fenici e Punici (Roma, 1979), 3. Consiglio, Nazionale delle Ricerche. Roma: 857-863.

Gllman, A. (1981): "The Development of Social Stratification in Bronze Age Europe". Current Anthropology, 22, 1: 1-23.

- (1993): "Cambio cultural y contacto en la Prehistoria de la Europa mediterránea”. Trabajos de Prehistoria, 50: 103-111.

GODELIER, M. (1974): Economia, fetichismo y religión en las sociedades primitivas, Siglo XXI. Madrid .

- (1981) "Instituciones económicas". En Panorama de la antropología cultural contemporánea, 4. Anagrama. Barcelona.

Gómez Bellard, C. (1990) La colonización fenicia en la isla de Ibiza, Ministerio de Cultura. Madrid.

- (1991) "La expansión cartaginesa en Sicilia y Cerdeña". V Jornadas de Arqueologia Fenicio-púnica (Ibiza, 1990). Trabajos del Museo Arqueológico de Ibiza, 25: 47-58.

González Prats, A. (1986): "Las importaciones y la presencia fenicia en la Sierra de Crevillente (Alicante)". Aula Orientalis, IV: 279-302.

- (1991) "La presencia fenicia en el Levante peninsular y su influencia en las comunidades indígenas". II Jornadas de Arqueología Fenicio-púnica (Ibiza, 1987). Trabajos del Museo Arqueológico de Ibiza, 24: 109-118.

Grotanell.., C. (1981): "Santuari e divinitá delle colonie d'Occidente". "La religione fenicia. Matrici orientale $e$ sviluppi occidentali". Atti del Colloquio in Roma, 1979, Roma: 109-133.

GruZinski, S. y Rouveret, A. (1976): “[Ellos son como niños] Histoire et acculturation dans le Mexique colonial et I'Italie Méridionale avant la romanisation". Mélanges de l'Ecole française de Rome, 88: 159-219.

Gudeman, S. (1981): "Antropología económica: el problema de la distribución”. En J.R. Llobera (comp.): Antropologia económica. Estudios etnográficos. Anagrama. Barcelona: 231-265.

Iudice Gamito, T. (1988): Social Complexity in Soutwest Iberia 800-300 BC. The case of Tartessos. British Archaeological Reports, 439. Oxford.

LÓPEZ CASTRO, J.L. (1992): "La colonización fenicia en la Península Ibérica: 100 años de investigación". La colonización fenicia en el sur de la Península Ibérica. 100 años de Investigación (Almería, 1990). Instituto de Estudios Almerienses: 11-80.
- (1993): "Difusionismo y cambio cultural en la protohistoria española: Tarteso como paradigma". En J. Alvar y J.M. Blázquez (eds.): Los enigmas de Tarteso. (átedra. Madrid: 39-68.

- (1995): Hispania Poena. Los fenicios en la Hispania romana. Crítica. Barcelona .

LOPE $\angle$ PARDO, F. (1987): Mauritania Tingitana: de mercado colonial púnico a provincia periférica romana. Univ. Complutense. Madrid.

- (1990): "Sobre la función del edificio singular de Cancho Roano (Zalamea de la Serena, Badajoz)”. Gerión, 8: 141-162.

- (1992) "Reflexiones sobre el origen de Lixus y su Delubrum Herculis en el contexto de la empresa comercial fenicia". Lixus (Larache, 1989). Collection de l'École Française de Rome, 166: 85-101. Roma.

Manfredi. L.I. (1994): "Tharros XVIII-XIX. II Laboratorio Tharros". Rivista di Studi Fenici, XXII: 205-217.

Mayet, F.; Tavares, C. y Makaroum. Y. (1993): "L'Etablissement phenicien d'Abul (Alcácer do Sal)". Dossier D'Archeologie: 22-25.

Meillassoux, C. (1972): "From reproduction to production: a Marxist approach to economic anthropology". Economy and Society, 1: 93-105.

- (1977): Mujeres, graneros y capitales. Siglo XXI. México.

MOREL. J.P (1984): "Greek Colonization in Italy and in the West (Problems of Evidence and Interpretation)". En T. Hackens, N.D. Holloway y R.R. Holloway (eds.): Crossroads of the Mediterranean. Lovaina: 123-161.

MURPhy, R.F. y STEWARD, H. (1981): "Caucheros y tramperos: dos procesos paralelos de aculturación”. En J.R. Llobera (comp.): Antropología económica. Estudios etnográficos. Anagrama. Barcelona: 201-230.

Pl.ÁcIDO, D. (1989): "Realidades arcaicas de los viajes míticos a Occidente". Gerión, 7: 41-51.

- (1993)a: "Los viajes griegos al extremo occidente: del mito a la Historia". I Coloquio de Historia Antigua de Andalucía (Córdoba, 1988). Cajasur/Univ. de Córdoba. Córdoba: 173-180.

- (1993)b: "La imagen griega de Tartessos". En J. Alvar y J.M. Blázquez (eds.): Los enigmas de Tarteso. Cátedra. Madrid: 81-89.

Pellicer, M. (1989): "El Bronce Reciente y los inicios del Hierro en Andalucía Occidental". En $\mathbf{M}^{\mathrm{a}}$ E. Aubet (coord.): 147-187.

Ramón, J. (1991): "El yacimiento fenicio de Sa Caleta". III Jornadas de Arqueología Fenicio-púnica (Ibiza, 1988). Trabajos del Museo Arqueológico de Ibiza, 24: 177-197.

Renfrew, C. (1984): "Arqueología social de los monumentos megalíticos”. Investigación y Ciencia, enero: 70-79.

Ruiz, A. y Molınos, M. (1993): Los Iberos. Análisis arqueológico de un proceso histórico. Crítica. Barcelona

Ruiz Delgado, M. (1989): "Las necrópolis tartésicas: prestigio, poder y jerarquías”. En $\mathrm{M}^{n} \mathrm{E}$. Aubet (coord.): 247-286.

Ruiz-Gálvez Priego, M. (1986): "Navegación y comercio entre el Atlántico y el Mediterráneo a fines de la Edad del Bronce". Trabajos de Prehistoria, 43: 9-42. 
- (1987): "Bronce atlántico y "cultura" del Bronce Atlántico en la Península Ibérica". Trabajos de Prehistoria. 44: $251-264$

Ruiz-Galvez Priego, M. y Gal.an Domingo, E. (1991): "Las estelas del Suroeste como hitos de vías ganaderas y rutas comerciales". Trabajos de Prehistoria, 48: 257 . 273.

Ruiz Mata. D. (1989): "Huelva: un foco temprano de actividad metalúrgica durante el Bronce Final". En M'E. Aubet (coord.): 209-243.

- (1991)a: "Los fenicios en la bahía de Cádiz, según el Castillo de Doña Blanca": II Jornadas de Arqueología Fenicio-Púnica (Ibiza, 1987). Trabajos del Museo Arqueológico de Ibiza, 24: 89-100.

- (1991)b: "El túmulo 1 de la necrópolis de Las Cumbres". IV Jornadas de Arqueologia Fenicio-púnica (Ibiza, 1989). Trabajos del Museo Arqueológico de Ibi$z a, 24:$ 207-220.

- (1993): "Proyecto: La colonización fenicia en la bahía de Cádiz a través del Castillo de Doña Blanca. Puerto de Santa María". Investigaciones Arqueológicas en Andalucía, 1985-1992. Proyectos. VI Jornadas de Arqueología Andaluza. Consejería de Cultura de la Junta de Andalucía. Huelva: 489-497.

Ruiz Mata, D. y Pérez, C. (1989): “El túmulo 1 de la necrópolis de Las Cumbres (Puerto de Santa María, Cádiz)". En M²E. Aubet (coord.): 287-295.

RowLANDS. M.J. (1971): "The archaeological interpretation of prehistoric metalworking". World Archaeology, 3: 210-224.

SAHLINS, M. (1972): Las sociedades tribales. Labor. Barcelona.

- (1977): Economía de la Edad de Piedra. Akal. Madrid.

- (1979): "Hombre pobre, hombre rico, gran hombre, jefe: tipos políticos de Melanesia y Polinesia". En J.R. Llobera (ed.): Antropología política. Anagrama. Barcelona: $267-288$.

SANTACana, J. (1995): "Difusión, aculturación e invasión: apuntes para un debate sobre la formación de las sociedades ibéricas en Cataluña". VIII Jornades d'Arqueologia fenício-púnica (Ibiza, 1994). Trabajos del Museo Arqueológico de Ibiza, 29: 145-163.

Terray, E. (1975): "Clases y consciencia de clases en el reino abron de Gyaman". En M. Bloch (ed.): Análisis marxistas y antropología social. Anagrama. Barcelona: 105-162.

Tsirkin, Ju.B. (1981): "Phönizier und Spanier. Zum Problem der kulturellen Kontakte". Klio, 63: 411-421.

W ACHTEL, N. (1978): “La aculturación”. En Le Goff y Nora (ed.): Hacer la historia, 1, Laia. Barcelona: 135-156.

WAGNER, C.G. (1983): "Aproximación al proceso histórico de Tartessos”. Archivo Español de Arqueología, 56: 3-36.

- (1986)a: "Tartessos y las tradiciones literarias". Rivista di Studi Fenici, XIV, 2 : 201-228.

- (1986)b: "Notas en torno a la aculturación en Tartessos”. Gerión, 4: 129-160.
- (1987): "Fenicios y cartagineses en la Península Ibérica. A próposito de una publicación reciente". Gerión, 5: 317-344.

- (1988): "Gadir y los más antiguos asentamientos fenicios al Este del Estrecho". Congreso Internacional El Estrecho de Gibraltar (Ceuta, 1987). Madrid, 1: 419428.

- (1989): "The Carthaginians in Ancient Spain. From Administrative Trade to Territorial Annexation". Punic Wars: Studia Phoenicia, X: 145-156.

- (1990): "La Jefatura como instrumento de análisis del historiador. Cuestiones teóricas y metodológicas". Espacio y organización social. Univ. Complutense. Madrid: 91-108.

- (1991): "La historia Antigua y la Antropología: el caso de Tartessos". Ias Jornadas de Aproximación interdisciplinar para el estudio de la Antigüedad. Kolaios (P.O.), 1: 1-37.

- (1991)b: "Writing and Problems of Acculturation in Tartessos". En Cl. Baurin; C. Bonet y V. Krings (eds.): Phoinikeia Grammata. Lire et écrire en Méditerranée, Societé d'Etudes Classiques. Lieja: 683-689.

- (1992): "Tartessos en la historiografía: una revisión crítica". La colonización fenicia en el sur de la Pe. nínsula Ibérica. 100 años de Investigación (Almería, 1990). Instituto de Estudios Almerienses: 81-103.

- (1993)a: "Las estructuras del mundo tartésico". En J. Alvar y J.M. Blázquez (eds.): Los enigmas de Tarteso. Cátedra. Madrid: 103-116

- (1993)b: "La implantación fenicia en Andalucía. ¿Esquema unidireccional o problemática compleja”. I Coloquio de Historia Antigua de Andalucía (Córdoba, 1988). Cajasur/Univ. de Córdoba: 81-94

- (1993)c: "Metodología de la aculturación. Consideraciones sobre las formas del contacto cultural y sus consecuencias". En J. Mangas y J. Alvar (eds.): Homenaje a J.M ${ }^{a}$ Blázquez, 1. Ed. Clásicas. Madrid: 445-464.

- (1993)d: "Aspectos socioeconómicos de la expansión fenicia en Occidente: el intercambio desigual y la colonización agrícola". Estudis d'Historia Economica (Univ. Baleares): 13-37.

- (1994): "El auge de Cartago y su manifestación en la Península Ibérica". VIII Jornadas de Arqueología Fenicio-Púnica (Ibiza, 1993). Trabajos del Museo Arqueológico de Ibiza, 33: 7-24.

- (e.p.): "Comercio, colonización e interacción cultural en el Mediterráneo antiguo. Ensayo de aproximación metodológica". En El Mediterráneo en la Antigüedad: marinos, colonos y comerciantes (Almería, 1992).

WAGNER, C.G. y Alvar, J. (1989): "Fenicios en Occidente: la colonización agrícola”. Rivista di Studi Fenici, XVII, 1: 61-102.

Whittaker, C.R. (1974): "The Western Phoenicians: Colonization and Assimilation". Papers of the Cambridge Phylological Society, 200 (n.s. 20): 58-79. 